\title{
Synergistic Smart Fuel for Microstructure Mediated Measurements
}

\section{0th Annual Review of Progress in Quantitative Nondestructive Evaluation Conference}

James A. Smith

Dale K. Kotter

Randall A. Ali

Steven L. Garrett

U.S. Department of Energy

National Laboratory

operated by

Battelle Energy Alliance

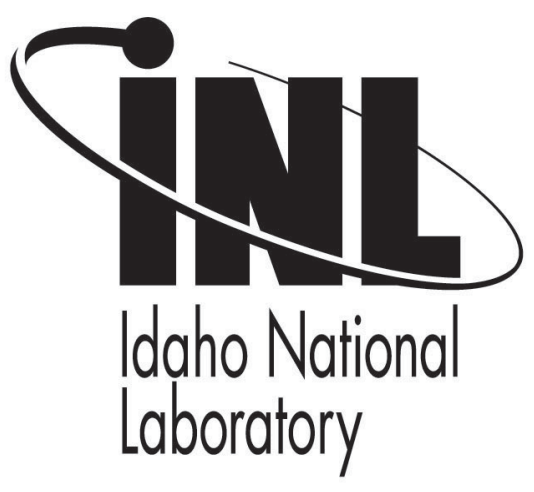

This is a preprint of a paper intended for publication in a journal or proceedings. Since changes may be made before publication, this preprint should not be cited or reproduced without permission of the author. This document was prepared as an account of work sponsored by an agency of the United States Government. Neither the United States Government nor any agency thereof, or any of their employees, makes any warranty, expressed or implied, or assumes any legal liability or responsibility for any third party's use, or the results of such use, of any information, apparatus, product or process disclosed in this report, or represents that its use by such third party would not infringe privately owned rights. The views expressed in this paper are not necessarily those of the United States Government or the sponsoring agency. 


\title{
Synergistic Smart Fuel for Microstructure Mediated Measurements
}

\author{
James A. Smith ${ }^{\mathrm{a}}$, Dale K. Kotter ${ }^{\mathrm{a}}$, Randall A. Ali ${ }^{\mathrm{b}}$, and Steven L. Garrett ${ }^{\mathrm{b}}$ \\ ${ }^{a}$ Idaho National Laboratory, Fuel Performance and Design, P.O. Box 1625, Idaho Falls Idaho, 83415-6188 \\ ${ }^{b}$ Graduate Program in Acoustics and Applied Research Laboratory, Penn State University, \\ P. O. Box 30, M/S 3520D, State College, PA 16804-0030
}

\begin{abstract}
Advancing the Nuclear Fuel Cycle and Next Generation Nuclear Power Plants requires enhancing our basic understanding of fuel and materials behavior under irradiation. The two most significant issues limiting the effectiveness and lifespan of the fuel are the loss of thermal conductivity of the fuel and the mechanical strength of both fuel and cladding. The core of a nuclear reactor presents an extremely harsh and challenging environment for both sensors and telemetry due to elevated temperatures and large fluxes of energetic and ionizing particles from radioactive decay processes. The majority of measurements are made in reactors using "radiation hardened" sensors and materials. A different approach has been pursued in this research that exploits high temperatures and materials that are robust with respect to ionizing radiation. This synergistically designed thermoacoustic sensor will be self-powered, wireless, and provide telemetry. The novel sensor will be able to provide reactor process information even if external electrical power and communication are unavailable. In addition, the form-factor for the sensor is identical to the existing fuel rods within reactors and contains no moving parts. Results from initial proof of concept experiments designed to characterize porosity, surface properties and monitor gas composition will be discussed.
\end{abstract}

Keywords: Sensor, Acoustics, Thermoacoustics, Synergistic, Microstructure, Fission gas, Nuclear, Thermometry, Nondestructive, Wireless, Thermal, Self-powered.

PACS: *43.60.Vx, 43.35.Ud, 28.41.Bm, 65.40.De

\section{INTRODUCTION}

Advancing the nuclear fuel cycle and next generation nuclear power plant requires enhancing our fundamental understanding of fuel and materials behavior under irradiation. The two most critical issues limiting the performance and lifetime of the fuel are the degradation of the thermal conductivity of the fuel and the mechanical integrity of both the fuel and cladding. To better understand thermal conductivity, we must have the means to perform highfidelity in-core temperature and microstructure measurements. Several technology barriers exist for implementation of sensors into reactor vessels, especially in high-neutron-flux regions. They include (1) high temperature materials and sensors that can operate up to $1500^{\circ} \mathrm{C}$, (2) radiation hardened materials and electronics, and (3) wireless communication methods compatible with harsh environments.

To better understand the mechanical integrity of fuels, we must have means to perform nondestructive analysis of the material. An efficient fuel must have the right microstructure within the reactor to perform properly. It is known that the evolution of defects in microstructures will change the material's overall porosity. This research demonstrates that changes in porosity can be detected with a heat-engine-based sensor and remotely monitored as changes in acoustic frequency and/or amplitude. Microstructure changes in fuel can be monitored directly, by sensing changes in porosity, or indirectly by monitoring fission-gas release. Initial experimentation has been performed using surrogate materials, representative of fuels/cladding, with precisely controlled porosity.

Instead of pursuing the adaption of existing technology, it has become increasingly evident that a paradigm shift is necessary to develop effective sensors for the harsh nuclear environment. The fundamental question that should drive sensor design is how the harsh environment can be used to the sensors' advantage. Instead of working against the environmental conditions, the sensor must be synergistic and take advantage of its environment as well as the intrinsic power source, cooling mechanisms and thermal gradients provided in the reactor core.

This research introduces a thermoacoustic (TAC) sensor that enables both high-temperature and porosity-sensing capabilities within a nuclear environment. The TAC requires no mechanical pump, moving parts, or electricity to provide a wireless indication of temperature. TAC sensors work synergistically with harsh in-pile environments and 
can potentially be incorporated within current cladding and capsule designs for in-pile use. The sensor is self powered by the temperature differential between the fuel and the coolant.

Since TAC devices can be constructed from robust materials and have no moving parts, they are ideally suited for the hostile conditions within a reactor. The existing geometry of the ATR experimental fuel rods and capsules make excellent acoustical resonator cavities. The temperature differential between the fuel $\left(\approx 1,000^{\circ} \mathrm{C}\right)$ and the cooling water $\left(\approx 60^{\circ} \mathrm{C}\right)$ in the ATR reactor will provide the ideal power source for the TAC device.

\section{THERMOACOUSTIC ENGINE}

TAC can be defined as the generation of acoustic waves from heat transfer. The TAC engine converts heat from a high-temperature source into acoustic power, while rejecting waste heat to a low-temperature sink (i.e., coolant) [1-3]. The temperature variation, imposed across a section of an acoustic cavity, drives heat into the gas, forcing the gas to do work on its surroundings and amplifying the acoustic oscillations. Each parcel of oscillating gas takes heat from the parcel behind and transfers it forward to adjacent gas molecules. Maintaining the steep thermal gradient by an external power source is necessary to induce TAC operation. For laboratory testing, the TAC device is powered by a resistive heater. In a reactor, fuel or gamma heating will power the TAC. The frequency generated by the TAC is related to temperature within the reactor [4].
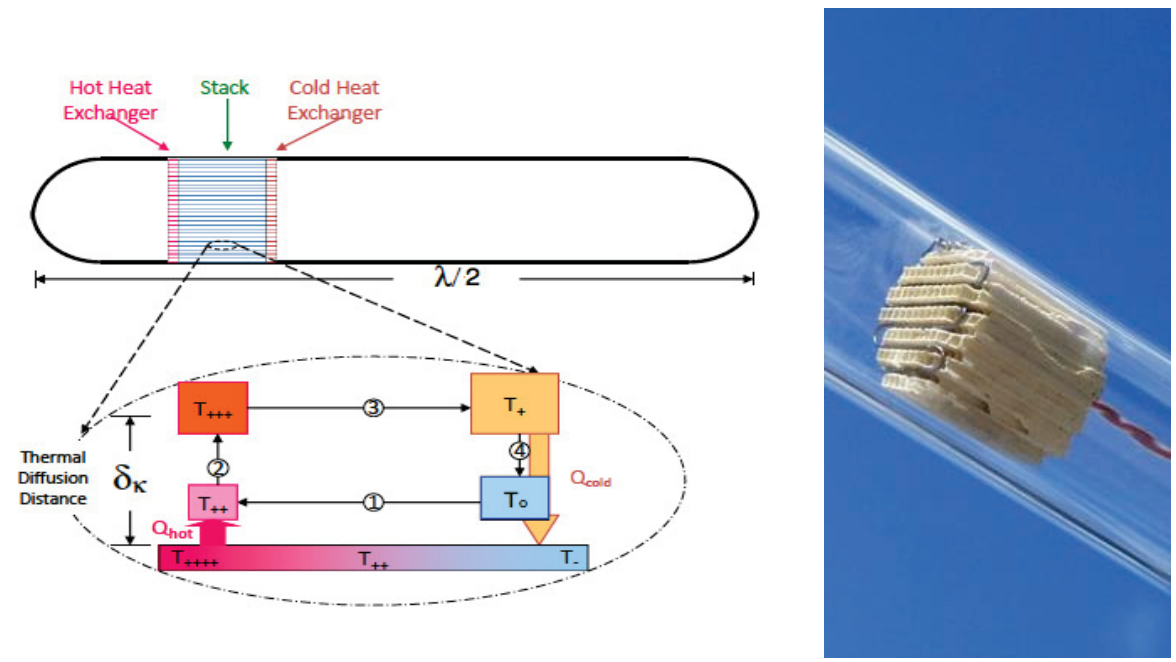

FIGURE 1. (Left) Half-wavelength resonator and the four part cycle of a gas parcel within the stack. (Right) ceramic stack material inside a test tube. (Photo courtesy of Reh-Lin Chen).

Figure 1 (Left) illustrates the operation of a stack-based TAC engine. The engine contains the stack material (Fig. 1 [Right]) and hot and cold heat exchangers in a closed-closed (half-wavelength) resonator [1,2]. The stack used consists of a regular array of parallel channels. These stacks are the substrates for catalytic converters found in cars and can be made from any channeled material with high heat capacity, such as glass or stainless steel. Heat is applied to the hot end of the stack and creates a temperature gradient across the stack. The stack's cold end needs to be maintained at a lower temperature. The TAC phenomenon is similar to a four-stroke car engine. Cool fuel gets injected and compressed to increase the gas temperature. As the gas reaches maximum compression, heat gets input (spark). As the combusted gas expands, gas temperature drops. The combusted gas and heat are exhausted. The cycle begins anew.

The four stroke TAC cycle can be illustrated using Fig. 1. When a gas parcel moves to the left (step 1), the parcel's temperature increases ( $\mathrm{To} \rightarrow \mathrm{T}++$ ) by adiabatic compression. Heat is then transferred from the hot end of the stack to the gas parcel during step 2. This increases the gas parcel's temperature $(\mathrm{T}++\rightarrow \mathrm{T}+++)$ and pressure. In step 2 , the gas parcel is at a stable high pressure. The increased temperature causes an increase in volume of the parcel. Consequently, work $(\mathrm{p} \Delta \mathrm{V})$ is done to the gas parcel by the flow of heat from the stack to the gas parcel. The pressure increase pushes the gas parcel back by slightly more each cycle.

The gas parcel then moves to the right (step 3) and is cooled $(\mathrm{T}+++\rightarrow \mathrm{T}+$ ) by adiabatic expansion. Heat is transferred from the parcel to the stack (step 4). This lowers the gas parcel's temperature ( $+\rightarrow \mathrm{To}$ ) and pressure. 
Since the removal of heat from the gas occurs at a fixed low pressure, the volume of the parcel is decreased. Work $(\mathrm{p} \Delta \mathrm{V})$ is done to the gas parcel. This pulls the gas back toward the hot end of the stack by slightly more each cycle. Eventually, the amplitude of the acoustic resonance grows to a steady-state level. Steady-state operation occurs when the acoustic energy dissipated during each cycle is equal to the TAC acoustic energy. Lord Rayleigh intuitively understood the TAC process in the 19th century [5] and stated a "vibration is encouraged when heat is added during compression and removed during rarefaction."

\section{EXPERIMENTAL PLAN AND SETUP}

Thermometry measurements have already been reported by using an experimental capsule designed for insertion into the core of the Advanced Test Reactor at the INL. The experimental capsule design has been modified to develop a prototype TAC thermometry sensor [4, 6-8]. Currently, testing for direct and indirect measure of microstructure will be performed. The direct measure of microstructure will be performed by inserting porosity specimens of various pore sizes into the hot end of the TAC's resonant cavity. The porosity specimens consist of various honeycombed steel pucks of fixed geometry. In addition, a dynamic porosity experiment will be performed using a porous puck that has been immersed in wax. The wax blocks the pores making a nonporous specimen. When the specimen is placed in the TAC sensor, the wax melts and runs out of the porosity specimen. Resulting modulation to the acoustic signal will be evaluated. The indirect measurement of microstructure will be simulating fission-gas release by filling the resonant cavity with different gases. The baseline gas will be atmospheric air.

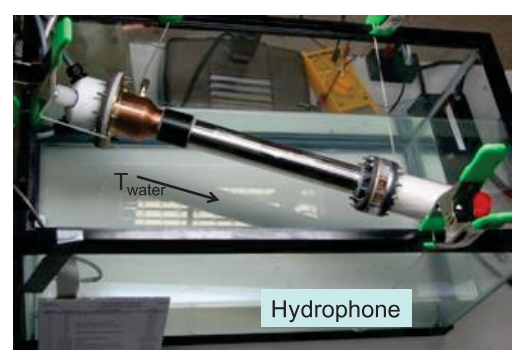

FIGURE 2. Submersible TAC sensor is shown suspended above the aquarium test tank prior to testing.

A water tank is used to simulate the reactor containment/coolant as shown in Fig. 2. The oscillatory movement of gas results in a "singing tube" that radiates acoustic energy into the water and into the room. A computer-controlled data acquisition system is configured to measure the TAC's internal static pressure, dynamic pressure, fundamental frequency and gas temperatures in several locations as well as recording the power applied to the heater.

\section{Porosity Experiments}

Leading causes of fuel failure is swelling, crack growth, and the deleterious interaction between the fuel and cladding. Methods to measure in-core microstructure properties are desired. TAC sensors must enable the linking of fundamental microstructural damage mechanisms to the macroscopic degradation of the fuel components to be useful. TAC's ability to characterize microstructure has been evaluated. Experiments were conducted by fabricating steel porosity specimens and placing them within the hot end of the TAC (Fig. 3). It should also be noted that specimens can be placed in the cold end of the TAC, thus enabling separate effects testing with a temperature differential on the order of $400^{\circ} \mathrm{C}$ at the same radiation flux.

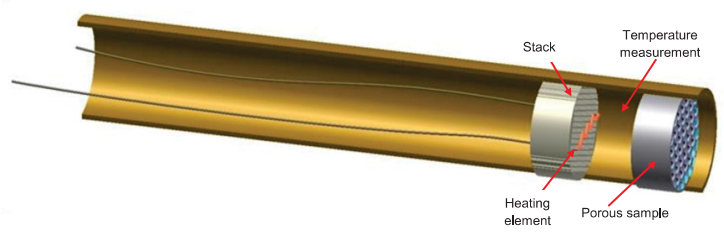

FIGURE 3. Porosity arrangement is displayed in graphic of the sample within the TAC for mediated microstructure measurements. 
Table I shows the results from the porosity experiments. Frequency invariants $[4,8]$ are recorded because the Ideal Gas Law predicts that the ratio of acoustic frequency to square root of absolute temperature is a constant. The hot end invariant is obtained from taking the frequency of the acoustic resonance and dividing it by the square root of the temperature in the hot end of TAC resonator (behind the heating coil). The cold end invariant is obtained in a similar manner. The spherical pores come in two sizes $(3.46 \mathrm{~mm}$ and $1.73 \mathrm{~mm}$ diameters) and two configurations (columns aligned and columns offset). The microstructural specimens are shown in Fig. 4.

TABLE I. Results from the TAC porosity experiments.

\begin{tabular}{ccccccc}
\hline $\begin{array}{c}\text { Specimen- } \\
\text { Porous Disks }\end{array}$ & $\begin{array}{c}\text { Weight } \\
\text { (grams) }\end{array}$ & $\begin{array}{c}\text { Geometry } \\
\text { Diameter } \times \\
\text { Height (mm) }\end{array}$ & $\begin{array}{c}\text { Cold End } \\
\text { Invariant }(\mathbf{H z} / \sqrt{\mathbf{K}})\end{array}$ & $\begin{array}{c}\text { Hot End } \\
\text { Invariant } \\
\text { (Hz/ } / \mathbf{K})\end{array}$ & $\begin{array}{c}\text { Hot } \\
\text { End Temp } \\
\text { (Celsius) }\end{array}$ & $\begin{array}{c}\text { Cold } \\
\text { End Temp } \\
\text { (Celsius) }\end{array}$ \\
\hline $\begin{array}{c}\text { Empty } \\
\text { (baseline) }\end{array}$ & N/A & N/A & 18.74 & 16.31 & 130 & 31.5 \\
$\begin{array}{c}\mathbf{1 . 7 3 m m} \\
\text { Aligned }\end{array}$ & 33.5 & $32 \times 12.7$ & 19.28 & 15.91 & 163 & 31.7 \\
\hline $\begin{array}{c}\mathbf{1 . 7 3 m m} \\
\text { Offset }\end{array}$ & 23 & $32 \times 12.7$ & 19.25 & 15.51 & 205 & 31.5 \\
$\begin{array}{c}\mathbf{3 . 4 6 m m} \\
\text { Aligned } \\
\mathbf{3 . 4 6 m m} \\
\text { Offset }\end{array}$ & 32 & $32 \times 12.7$ & 19.27 & 16.1 & 172 & 32.0 \\
\hline
\end{tabular}

Table I illustrates that the TAC exhibits different behavior in the presence of porous samples within the TAC and with microstructure configuration. The immediate feature that is clearly reinforced by the table is the robust nature of the cold end invariant. Significant variations in the measurements occur in the hot end. There is significant variation between the two $1.73 \mathrm{~mm}$ pore alignments in hot-end invariants and temperatures. There does not appear to be any significant variations between $3.46 \mathrm{~mm}$ pore alignments.

Table II shows a number of interesting trends. Note that the cold-end invariant tends to follow the mass of the object inserted into the TAC engine while the other parameters do not show an obvious correlation with mass. The hot-side measurements tend to be independent of the placement of the specimen (with and without spacer). The placement of foil over the pucks' front surfaces had the largest effect on the hot-end measurements. The effects from the foil are strong indications that the hot end is sensitive to surface microstructure. The cold-end temperature remains consistent near the water temperature. It is interesting to note the long puck has the largest effect on the cold-end invariant.

It is also interesting to note that hot-end temperatures with the porous pucks tend to run hotter than solid pucks [9-10]. The solid puck hot-end temperatures clearly show that loss of convective flow has a minimal impact on hotend temperature when compared to baseline data. The exception is the foil-covered specimen where another heat transfer mechanism is clearly involved. Thus, there are strong indications that the hot end is sensitive to bulk and surface microstructure.

\section{Dynamic Microstructure Experiments}

The porosity specimen consists of a honeycombed puck ( $3.46 \mathrm{~mm}$ aligned pores) that has been immersed in wax. (Fig. 4) The wax blocks the pores, making a nonporous specimen. When the specimen is placed in the TAC sensor, the wax melts and runs out of the specimen.

Resulting modulation to the acoustic signal has been noted, as shown in Fig. 5. The salient phenomenon is that the movement of the melting wax perturbed the cavity such that the sonic resonance is temporarily extinguished. Once the melted wax stopped flowing, the resonance started back up, but at a slightly higher frequency. The waxmelt data show that the TAC engine can clearly track dynamic bulk microstructural (opening of interconnect pores) events. 
TABLE II. Behavior of mock-up fuel pellets of various dimensions and weights. Spacer serves as a TAC resonator standoff (5 gm mass)

\begin{tabular}{|c|c|c|c|c|c|c|}
\hline $\begin{array}{r}\text { Specimen } \\
\text { (Solid Pucks) }\end{array}$ & $\begin{array}{c}\text { Geometr } \\
y \\
\text { Diameter } \times \\
\text { Height }(\mathrm{mm}) \\
\end{array}$ & $\begin{array}{l}\text { Weight } \\
\text { (grams) }\end{array}$ & $\begin{array}{l}\text { Cold End } \\
\text { Invariant } \\
(\mathbf{H z} / \sqrt{ } \mathbf{K})\end{array}$ & $\begin{array}{l}\text { Hot End } \\
\text { Invariant } \\
(\mathbf{H z} / \sqrt{ } \mathbf{K})\end{array}$ & $\begin{array}{l}\text { T Hot } \\
\text { End } \\
\text { (Celsius) }\end{array}$ & $\begin{array}{c}\text { T } \\
\text { Cold } \\
\text { End } \\
\text { (Celsius) } \\
\end{array}$ \\
\hline Long, with spacer & $32 \times 25.4$ & 86 & $\begin{array}{c}\text { NA } \\
\text { (acoustic } \\
\text { onset never } \\
\text { achieved) }\end{array}$ & NA & 248.8 & 34.2 \\
\hline Long, no spacer & $32 \times 12.7$ & 81 & 19.4 & 16.5 & 153.7 & 29.5 \\
\hline $\begin{array}{l}3.46 \mathrm{~mm} \text { Aligned } \\
\text { Porous puck and foil, } \\
\text { with spacer }\end{array}$ & $32 \times 25.4$ & 39 & 19.25 & 14.5 & 236.4 & 33.3 \\
\hline $\begin{array}{l}3.46 \mathrm{~mm} \text { Aligned } \\
\text { Porous puck and foil, } \\
\text { no spacer }\end{array}$ & $32 \times 12.7$ & 34 & 19.3 & 14.65 & 236.0 & 33.1 \\
\hline Short, spacer & $32 \times 15.8$ & 17 & 19.2 & 16.4 & 143.7 & 32.3 \\
\hline Short, no spacer & $32 \times 3.1$ & 12 & 19.05 & 16.3 & 144.2 & 33.6 \\
\hline $\begin{array}{l}80, \text { long term } \\
\text { baseline (empty) }\end{array}$ & NA & NA & 19.1 & 16.2 & 145 & 29.0 \\
\hline
\end{tabular}

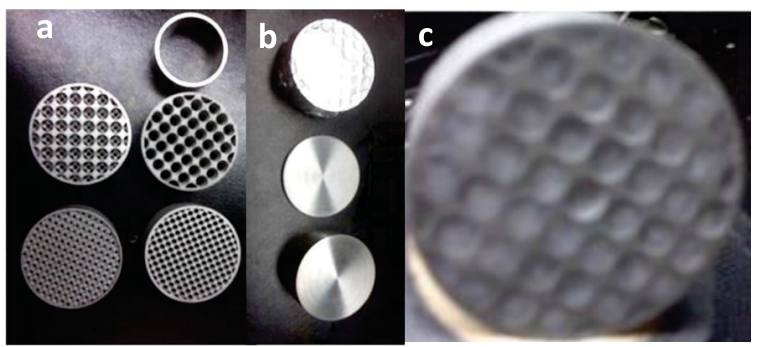

FIGURE 4. Photographs of microstructure specimens and spacers used for testing. a) Samples representing interconnected porosity. b) Samples representing surface microstructure and used as spaces. A low density solid puck was simulated by wrapping a $3.46 \mathrm{~mm}$ aligned porous specimen with tin foil (Top). c) Picture of $3.46 \mathrm{~mm}$ aligned pores porosity specimen with wax filled pores. (Diameter of specimen is $32 \mathrm{~mm}$, the height is $12.7 \mathrm{~mm}$.)

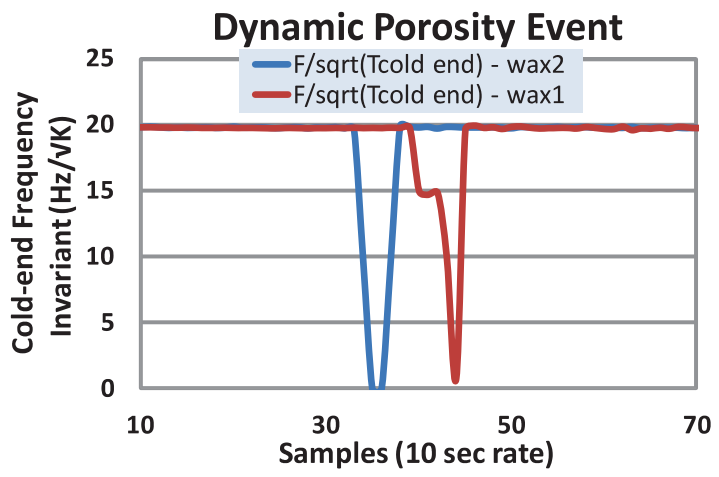

FIGURE 5. Plot shows the frequency invariant of the wax filled porosity specimen with time. As the porosity specimen heats up, the wax melts. The flowing wax keeps the TAC sensor from resonating and the signal drops out near 35 to $45 \mathrm{Sa}$. Once the liquid wax has finished flowing, the cavity is stabilized and sound resonance restarts. However the recovered signal has slightly more variation. 


\section{Gas Density Experiments}

The TAC strategy can be extended to remote sensing of fission-gas (particularly krypton and xenon) evolution as part of the radioactive decay of the fuel [11] although, to separate effects, pairs of fuel-rod resonators may be required (e.g., one to measure temperature and the other to identify gas mixture concentration). An indirect measure of microstructure evolution is simulated by filling the resonant cavity with various gasses. The TAC technique has merit because the Universal Gas Constant is determined from the measurement of acoustical resonances at the National Institute of Standards and Technology [12]. Future TAC designs will measure the rate of production of fissile gases, krypton and xenon, which are influenced by microstructural changes.

Initial experiments performed at the INL confirm the practicality for fission-gas monitoring, as shown in Table III. The tabulated data show that resonance frequency is directly related to the ratio of the square root of the polytropic coefficient $\left(\gamma=c_{P} / c_{V}\right)$ to the mean molecular mass, M, of the gases. Evolving the gas within the TAC resonator will result in variations in the frequency of the sound radiated. The measured frequency ratios are not exactly equal to those based on the properties of the gases due to the fact that the temperatures during all four measurements were nearly, but not exactly, equal and the humidity of the air sample was unknown. Although "dry" air has a molecular weight larger than nitrogen, the presence of humidity in the air dropped the average molecular weight below nitrogen. TAC demonstrates the ability to resolve atmospheric air ( $\sim 70 \%$ nitrogen) from pure nitrogen and moisture content. Thus, the TAC sensor can also be a humidity sensor if properly configured.

Accurate in situ measurement of fission-gas release will enable the prediction of microstructure evolution and support development of fuel microstructure that can be designed to maximize fuel lifetime and reliability. The TAC engine can clearly differentiate gas molecules and mixtures that may result from microstructure changes and fission gas release.

TABLE III. Acoustic frequency variation is shown for four different gases. The ratio of the measured frequencies to the frequency in helium is compared to the ratio calculated using molecular mass and the ratio of specific heats, $\gamma=c_{P} / c_{V}$.

\begin{tabular}{cccccc} 
Molecular & $\begin{array}{c}\text { Polytropic } \\
\text { Mass }\end{array}$ & $\begin{array}{c}\text { Coefficient } \\
\left(\gamma=c_{P} / c_{V}\right)\end{array}$ & $\begin{array}{c}\text { Ave. Freq. } \\
(\mathrm{Hz})\end{array}$ & $\begin{array}{c}\text { Freq. Ratio } \\
f / f_{\mathrm{He}}\end{array}$ & $\begin{array}{c}\text { Sq. Root } \\
\text { Ratio } \\
(\gamma / M)^{0.5}\end{array}$ \\
\hline \hline Helium & 4.00 & 1.667 & 976.2 & 1.000 & 1.000 \\
Nitrogen & 28.01 & 1.400 & 315.7 & 0.323 & 0.346 \\
(Dry) Air* & 28.96 & 1.403 & $\mathbf{3 2 2 . 7}$ & $\mathbf{0 . 3 3 1}$ & 0.341 \\
Xenon & 131.29 & 1.667 & 173.0 & 0.177 & 0.175
\end{tabular}

* Humid room air was used in the experiment

Note that the results for "room" air are slightly larger than nitrogen due to natural humidity.

\section{CONCLUSIONS}

A novel sensor based on thermoacoustic phenomenon has been demonstrated. The TAC sensor is shown to be synergistic with conditions within a nuclear reactor. TAC technology takes advantage of the large thermal gradients caused by the nuclear fuel and surrounding cooling water and, therefore, requires no external power source. Because the phenomenon is simplistic and has no moving parts, the sensor can be constructed from inexpensive, yet robust materials. The signal generated is acoustic and, thus, is transmitted efficiently through the cooling water or metal pipes/structures within the reactor.

Although there are a few labs worldwide working with TAC technology as applied to heat engines, the INL is the only known laboratory that is developing TAC sensors. Novel process (temperature, gas-composition, extension, pressure, etc.) and microstructure sensors have been developed and successfully tested at INL. The TAC engine can also be used for separate effects testing by providing hot and cold regions within the resonant cavity that have a temperature differential of $\approx 400^{\circ} \mathrm{C}$ with similar radiation flux. Thus, a whole new measurement-architecture paradigm has been opened from the ability to have heat-engine-based wireless and self-powered sensors. The new sensing-architecture paradigm will reduce experiment complexity and be simple, robust, easy to install, and costeffective.

The experiments discussed have been designed to demonstrate the microstructure-characterization potential of TAC sensors. Two types of microstructure monitoring have been evaluated. Both direct monitoring of effects from 
interconnected porosity and indirect microstructure characterization from fission-gas composition have been demonstrated. The TAC sensor properly ordered, based on molecular weight, and differentiated these gasses: nitrogen, helium, xenon, and atmospheric air. The TAC sensor has sufficient fidelity to clearly differentiate between nitrogen and atmospheric air. Dynamic microstructure evolution has also been monitored.

Since the TAC sensor is robust, wireless, self-powered and economical, the TAC sensor is an excellent choice as a new approach for in-pile monitoring within a nuclear reactor. The natural and synergistic properties of the TAC engine provide the confidence that testing within a reactor will be successful. A TAC sensor specifically designed for the Very High Temperature Reactor Program is scheduled to go into a laboratory mock-up of an Advance Gas Reactor test train in the winter of 2013. The Separate Effects Testing prototype for the Fuel Cycle Research and development program is scheduled for insertion in 2015.

\section{ACKNOWLEDGEMENTS}

Work is sponsored by the Department of Energy Office of Nuclear Energy: Fuel Cycle Research and Development and Very High Temperature Reactor Programs.

\section{REFERENCES}

1. G. W. Swift, Thermoacoustics: A unifying perspective for some engines and refrigerators (Acoustical Society of America through the American Institute of Physics, 2002); ISBN 0735400652.

2. S. L. Garrett and S. Backhaus, "The Power of Sound," American Scientist, 88(6), 516-525 (2000).

3. S. L. Garrett, "Resource Letter TA-1: Thermoacoustic engines and refrigerators," Am. J. Phys. 72(1), 11-17 (2004).

4. R. A. Ali, S. L. Garrett, J. A. Smith, and D. K. Kotter, "Thermoacoustic thermometry for nuclear reactor monitoring," IEEE J. Instrumentation \& Measurement 16(3), 18-25 (2013).

5. J. W. Strutt (Lord Rayleigh), Theory of Sound, Vol. II (Dover reprint, New York, 1945) §322.

6. R. A. Ali and S. L. Garrett, "Heat transfer enhancement through thermoacoustically-driven streaming," Proc. Mtgs. Acoust. 19, 030001 (2013).

7. S. L. Garrett, J. A. Smith, and D. K. Kotter, "Thermoacoustic Enhancements for Nuclear Fuel Rods and other High Temperature Applications,” U.S. Patent Application Serial No. 13/968,936 (Aug. 16, 2013); PCT/US2013/055352.

8. R. A. Ali, S. L. Garrett, J. A. Smith and D. K. Kotter, "Thermoacoustic device for nuclear fuel monitoring and heat transfer enhancement," J. Acoustical Soc. of America. 132(3) 1993(2012).

9. Gopinath, N. L. Tait, and S. L. Garrett, "Thermoacoustic streaming in a resonant channel: The time-averaged temperature distribution", J. Acoust. Soc. Am. 103(3), 1388-1405 (1998).

10. G. Penelet, M. Guedra, V. Gusev, and T. Devaux, "Simplified account of Rayleigh streaming for the description of nonlinear processes leading to steady state sound in thermoacoustic engines", Int. J. Heat and Mass Transfer 55, 6042-6053 (2012).

11. W. M. Stacey, Nuclear Reactor Physics, 2nd ed., (Wienheim: Wiley \& Sons Inc., 2007).

12. M. R. Moldover, et al., "Measurement of the Universal Gas Constant R using a spherical acoustic resonator," Phys. Rev. Lett. 60(4), 249-252 (1988). 